DOI: 10.20472/IAC.2017.032.026

SUNG SOO LIM

American University in Dubai, United Arab Emirates

\title{
THE EFFECTS OF ADULT MORBIDITY ON WORK HOURS OF CHILDREN IN INDONESIA
}

\begin{abstract}
:
In many developing countries, the burden of morbidity of prime-age adults is greater than in developed countries. Morbidity is distinct from other types of negative demographic shocks such as a loss of family members or dissolution of the family. Since the duration of illness and the possibility of recovery are generally difficult to anticipate, households may be more burdened in adjusting to the crisis caused by adult morbidity than they are to other types of demographic shocks or income shocks. Households with health shocks may use various coping strategies according to the nature of the costs imposed by those shocks. Among others, intra-household labor substitution may be an important coping strategy for households with limited access to other coping strategies. Moreover, the use of labor as insurance may have a negative impact on children's educational attainment, which has serious implications for the future welfare of the poor in developing countries. Yet, studies on this link between adult morbidity and child labor are rare.
\end{abstract}

Using two waves $(2007,2014)$ of Indonesian Family Life Survey data, this study investigates the effects of prime-age morbidity on work hours of children under 16 years old. This study is distinguished from few existing studies in the literature in that it controls for duration and severity of morbidity in the estimation of morbidity effects. Employing both self-reported health measures and measures of individuals' physical abilities to perform activities of daily living (ADLs), this study finds that work hours of children increase significantly when spouses of household heads suffer from long and severe illnesses. The effects are found to be greater for households where the spouses are not covered by any health insurance. Moreover, this study sheds light on gender roles within households coping with health shocks. In particular, it shows that work hours of male and female children increase more when household heads and their spouses suffer from health shocks, respectively. Again, the effects are found to be greater for households with no health insurance.

This study is of special interests to policy makers trying to identify households and individuals who are more vulnerable to unexpected health shocks. The results imply that benefits of government expenditures on healthcare may be greater when the Indonesian government, with its limited resources, targets subsidies towards households suffering severe and long-term morbidity shocks.

\section{Keywords:}

morbidity, child labor, intra-household labor substitution, Indonesia

JEL Classification: 100, 012 